\title{
External Beam Partial Breast Irradiation Versus Whole Breast Irradiation for in Early Breast Cancer区 A Systematic Review and Meta-Analysis
}

\section{Peiling Dai ( $\Delta 731015726 @ q q . c o m)$ \\ yunnan cancer hospital}

\section{Kai Chen}

the second affiliated hospital of wenzhou medical university

Lan Li

Yunnan Cancer Hospital

Li Wang

Yunnan Cancer Hospital

Yaoxiong Xia

Yunnan Cancer Hospital

Yu Hou

Yunnan Cancer Hospital

Lan Zhang

Yunnan Cancer Hospital

Li Chang

Yunnan Cancer Hospital

wenhui Li

Yunnan Cancer Hospital

\section{Research}

Keywords: External beam Partial Breast Irradiation, Whole breast irradiation, breast cancer

Posted Date: January 19th, 2021

DOI: https://doi.org/10.21203/rs.3.rs-147695/v1

License: (c) (1) This work is licensed under a Creative Commons Attribution 4.0 International License.

Read Full License 


\section{Abstract}

\section{Purpose}

Postoperative radiotherapy can reduce the recurrence of breast cancer. Postoperative radiotherapy is divided into whole breast irradiation (WBI) and partial breast irradiation (PBI) for early breast cancers. Due to the characters of saving time, money, and easy to deliver, external beams PBI (EB PBI) is brought into focus. However, the researches on outcomes, safety, and efficacy between EB PBI and WBI are still insufficient. We concluded a meta-analysis for LRR, regional node recurrence, contralateral breast cancer, distant recurrence, mortality, less acute skin toxicity ( $\nabla 1$ grade), late skin toxicity and the cosmetic score of external beam partial breast irradiation (EB PBI) and whole breast irradiation(WBI) to develop a radiotherapy plan for early low recurrence risk breast cancer patients.

Method

We searched Pubmed $\square$ Embase $\square$ Cochrane Library $\square$ Clinicaltrals. Study eligibility criteria are as below: (1) RCTs for EB PBI vs WBI; (2) Histologically confirmed breast cancer; (3) AJCC staged Tis-2NO-1M0; (4) Z 40 years old; (5) Tumor size $\leq 3 \mathrm{~cm}$;(6) microscopically clear margins $\leq 5 \mathrm{~cm}$; (7) Mean follow-up time $\sqrt{5}$ years. All data is used by Cochrane's Review Manager 5.3 (RevMan) to process.

Results

There were 4 RCT studies included in our study with 1999 patients in EB PBI group and 1999 patients in EB PBI. There was no statistic difference between $\mathrm{PBI}$ and WBI groups in local recurrence rates $(\mathrm{RR}=1.15$; $95 \% \mathrm{Cl}, 0.76$ to $1.74 ; p=0.52 ; I^{2}=0 \%$, regional node recurrence $\left(\mathrm{RR}=1.00 ; 95 \% \mathrm{Cl}, 0.49\right.$ to $2.04, p=0.99, \mathrm{I}^{2}$ $=0 \%)$, contralateral breast cancer $\left(\mathrm{RR}=0.79 ; 95 \% \mathrm{Cl}, 0.54\right.$ to $\left.1.16 ; \mathrm{p}=0.23 ; \mathrm{I}^{2}=0 \%\right)$, distant recurrence $(\mathrm{RR}$ $=1.00 ; 95 \% \mathrm{Cl}, 0.63$ to $\left.1.59 ; \mathrm{p}=1.00 ; \mathrm{I}^{2}=0 \%\right)$, non-breast second cancer $(\mathrm{RR}=1.03 ; 95 \% \mathrm{Cl}, 0.50$ to $2.16 ; \mathrm{p}$ $=0.93 ; \mathrm{I} 2=83 \%)$, mortality $\left(\mathrm{RR}=0.96 ; 95 \% \mathrm{Cl}, 0.60\right.$ to $\left.1.55 ; \mathrm{p}=0.88, \mathrm{I}^{2}=54 \%\right)$. EB PBI had worse cosmetic score $\left(\mathrm{RR}=1.56 ; 95 \% \mathrm{Cl}, 1.04\right.$ to $\left.2.34 ; \mathrm{p}=0.003, \mathrm{I}^{2}=84 \%\right)$, less acute skin toxicity ( 1 grade) $(\mathrm{RR}=0.17$; $95 \% \mathrm{Cl}, 0.07$ to $\left.0.42 ; \mathrm{p} \otimes 0.0001, \mathrm{I}^{2}=87 \%\right)$ and late skin toxicity $\left(\mathrm{RR}=0.65 ; 95 \% \mathrm{Cl}, 0.48\right.$ to $0.88 ; \mathrm{p}=0.005 ; \mathrm{I}^{2}$ $=27 \%)$ than $\mathrm{WBI}$.

\section{Conclusion}

EB PBI has similar LRR, regional node recurrence, contralateral breast cancer, distant recurrence, nonbreast second cancer and mortality with WBI. But EB PBI has worse cosmetic score, less acute skin toxicity ( $\mathbb{1}$ grade) and late skin toxicity than WBI.

\section{Introduction}

Breast cancer ranks second of the world in cancer incidence and mortality, with more than 2.08 million new cases and more than 630,000 deaths in $2018^{1}$. Irradiation can significantly reduce ipsilateral tumor 
recurrence and mortality of early breast cancer after breast-conserving surgery ${ }^{2-4}$. The delay of radiotherapy after breast-conserving surgery was associated with a significantly increased risk of local recurrence ${ }^{5}$. NCCN guideline-recommended radiotherapy after most of the early breast cancer patients after surgery, especially for breast-conserving surgery ${ }^{6}$. For early breast cancer patients with low recurrence risk, Partial breast irradiation $(\mathrm{PBI})$ is another choice than traditional whole breast irradiation $(\mathrm{WBI})^{6-8}$. The proposed of PBI were based on that the recurrence and metastasis sites after breastconserving surgery is usually located around the primary tumor. About $90 \%$ of recurrence was located in $1 \mathrm{~cm}$ from the primary tumor ${ }^{7,9-12}$. PBI just covers the primary tumor and its surrounding $2-3 \mathrm{~cm}$ area. $\mathrm{PBI}$ can shorten the time of radio-chemotherapy, reduce the treatment cost, and easy to deliver for most radiotherapy centers ${ }^{13}$. The above advantages and fewer irradiation tissues also improved patients' compliance with postoperative radiotherapy, chemotherapy, and life quality ${ }^{5,14}$. Although PBI had lower mortality without breast cancer recurrence, However, PBI had higher local recurrence and bad cosmetology outcomes than WBI in previous studies ${ }^{15,16}$. Vaidya J.S et al ${ }^{17}$ found that PBI compared to WBI reduced the overall mortality of without breast cancer patients by 25 percent over five years. Liu et $\mathrm{al}^{18}$ found there was no significant difference in lymph node recurrence, systemic recurrence, and overall survival or mortality. Pan XB et al ${ }^{19}$ found that the risk of secondary malignancy was similar for both $\mathrm{PBI}$ and WBI. Hickey $\mathrm{BE}$ et $\mathrm{al}^{20}$ found $\mathrm{PBI}$ or accelerated partial breast irradiation (APBI) has worse cosmetic and some late effects, but it has less acute skin toxicity.

PBI can be divided into brachytherapy PBI (implantation, single-cavity, multi-cavity balloons or combined application), intraoperative PBI (IORT), External beam PBI (EB PBI). However, EB PBI has the advantages of non-invasive and easy to deliver in most radiation centers ${ }^{21}$. It also had the shortest time and economic costs for patients than WBRT-B, WBI, WBI-accelerated, WBRT intensity-modulated, (APBI)-IC, APBI-HDR interstitial ${ }^{22}$. EB PBI has a huge application prospect of early breast irradiation than brachytherapy PBI and IORT. Up to now, no systematic meta-analysis on outcomes efficacy and toxicity effects of EB PBI and WBI have been reported. Recently, the latest results of the RAPID were published ${ }^{23}$, we concluded a meta-analysis for EB PBI and WBI for radiotherapy of early low recurrence risk breast cancer patients.

\section{Methods}

This paper is reported in accordance with the preferred reporting items for systematic reviews and metaanalyses (PRISMA) statement and was registered at the International Prospective Register of Systematic Reviews (number:156882).

We searched Pubmed (January 2021 to February 1995)【Embase (January 2021 to July 1994) $\square$ Cochrane Library (January 2021 to 2005) $\square$ Clinicaltrals (January 2021 to June 2015). Study eligibility criteria are as below: (1) RCTs for EB PBI vs WBI; (2) Histologically confirmed breast cancer; (3) AJCC stages Tis-2NO1M0; (4) $\geq 40$ years old; (5) Tumor size $\leq 3 \mathrm{~cm}$;(6) microscopically clear margins $\leq 5 \mathrm{~cm}$; (7) Mean followup time $₫ 5$ years. Search major themes included 'partial breast irradiation' OR accelerated partial breast 
irradiation' AND 'whole breast irradiation' And 'Breast Neoplasm' (randomized or randomized). MeSH Terms and Emrew terms were used. Then we selected articles in EB PBI vs WBI.

Two independent reviewers collected the data independently. Then they determined the data be included together. We tried to contact the authors to get not reported data. For papers that were updated or republished, the newest data was abstract. Cochrane's Review Manager 5.3 (RevMan) was used to assess statistical variance, risk ratios, heterogeneity and sensitivity. Homogeneity and sensitivity analysis were not described in detail because that the study we included was limited and small.

At last 4 papers were included (Fig. 1, Table 1), and all of them are RCTs. The outcomes were about the local regional rate (LRR), regional node recurrence, contralateral breast cancer, distant recurrence, and mortality. The results of the cosmetic score, acute skin toxicity ( $\nabla 1$ grade), and late skin toxicity also was included in our meta-analysis. $P$ values of less than 0.05 were considered statistically significant.

Table 1

Characteristics of included Studies

\begin{tabular}{|c|c|c|c|c|c|c|}
\hline $\begin{array}{l}\text { Study, } \\
\text { year }\end{array}$ & $\begin{array}{l}\text { Median } \\
\text { follow- } \\
\text { up } \\
\text { (years) }\end{array}$ & Age(years) & $\begin{array}{l}\text { Numbers } \\
\text { of } \\
\text { patients }\end{array}$ & $\begin{array}{l}\text { Irradiation } \\
\text { technology }\end{array}$ & WBI & PBI \\
\hline $\begin{array}{l}\text { Rodriguez } \\
N^{[1]}, 2013\end{array}$ & 5 & 61 & $\begin{array}{l}1065 \text { vs } \\
1070\end{array}$ & 3D-CRT & $48 \mathrm{~Gy} / 24 \mathrm{f}, \mathrm{QD}$ & $37.5 \mathrm{~Gy} / 10 \mathrm{f}, \mathrm{BID}$ \\
\hline $\begin{array}{l}\text { Livi L[2], } \\
2015\end{array}$ & 5 & $\geq 40$ & $\begin{array}{l}260 \text { vs } \\
260\end{array}$ & IMRT & $\begin{array}{l}50 \mathrm{~Gy} / 25 \mathrm{f} \\
\mathrm{QD}+ \\
10 \mathrm{~Gy} / 5 \mathrm{f}, \mathrm{QD}\end{array}$ & $30 \mathrm{~Gy} / 5 \mathrm{f}, \mathrm{QD}$ \\
\hline $\begin{array}{l}\text { Coles } \\
C^{[3]} \\
2017\end{array}$ & 5 & $\begin{array}{l}68.64 \pm \\
5.8\end{array}$ & 51 vs51 & IMRT & $\begin{array}{l}40 \mathrm{~Gy} / 15 f \\
Q D\end{array}$ & $40 \mathrm{~Gy} / 15 \mathrm{f}, \mathrm{QD}$ \\
\hline $\begin{array}{l}\text { TJ } \\
\text { W }^{[4]}, 2019\end{array}$ & 8.6 & 61 & $\begin{array}{l}1065 \text { vs } \\
1070\end{array}$ & $\begin{array}{l}\text { 3D-CRT/ } \\
\text { IMRT }\end{array}$ & $\begin{array}{l}\text { 42.5 Gy/16f, } \\
\text { QD }\end{array}$ & $38.5 \mathrm{~Gy} / 10 \mathrm{f}, \mathrm{BID}$ \\
\hline
\end{tabular}

\section{Results}

\section{Local recurrence rates}

There are 3 studies reported local recurrence rates of a total of 3998 patients. local recurrence was defined as any recurrence of the ipsilateral breast or overly skin. Meta-analysis show there was no statistic difference between $\mathrm{PBI}$ and $\mathrm{WBI}$ groups in local recurrence rates (relative risk $[R R]=1.15 ; 95 \%$ confidence interval $[\mathrm{Cl}], 0.76$ to $1.74 ; p=0.52 ; \mathrm{I}^{2}=0 \%$ ). During at least 5 years of follow-up, there was no significant difference between $\mathrm{EB} \mathrm{PBI}$ and $\mathrm{WBI}$ in the local recurrence rate.

\section{Regional node recurrence}


We defined regional node recurrence as recurrences of the axilla, supra clavicular fossa, and internal mammary chain. Meta-analysis show there was no statistic difference between EB PBI and WBI groups $\left(\mathrm{RR}=1.00 ; 95 \% \mathrm{Cl}, 0.49\right.$ to $2.04, \mathrm{p}=0.99, \mathrm{I}^{2}=0 \%$ ).

\section{Contralateral breast cancer}

There are 3 studies reported on Contralateral breast cancer. No statistic difference between EB PBI and WBI groups ( $R R=0.79 ; 95 \% \mathrm{Cl}, 0.54$ to $\left.1.16 ; p=0.23 ; I^{2}=0 \%\right)$.

\section{Distant recurrence}

Any recurrence of distant organs was considered as distant recurrence. There was no statistic difference between $\mathrm{EB} P B \mathrm{~B}$ and $\mathrm{WBI}$ groups ( $\mathrm{RR}=1.00 ; 95 \% \mathrm{Cl}, 0.63$ to $\left.1.59 ; \mathrm{p}=1.00 ; \mathrm{I}^{2}=0 \%\right)$.

\section{Non-breast seconded cancer}

There was no statistical difference in non-breast second cancer between EB PBI and WBI groups (RR = $1.03 ; 95 \% \mathrm{Cl}, 0.50$ to $2.16 ; \mathrm{p}=0.93 ;\left.\right|^{2}=83 \%$ ).

\section{Mortality}

Mortality was reported for 3 studies with a total of 3998 patients. there was no statistic difference between EB PBI and WBI groups. There was no statistic difference between EB PBI and WBI groups in mortality ( $R R=0.96 ; 95 \% \mathrm{Cl}, 0.60$ to $\left.1.55 ; p=0.88, \mathrm{I}^{2}=54 \%\right)$.

\section{Cosmetic scores}

Cosmetic outcome was evaluated on the Harvard Breast Cosmesis Scales ${ }^{23-26}$. It included size, shape, texture, edema, color, thickening, scar, and change into the appearance of the breast. It can be used for accurate cosmetic grading for patients that are treated with breast-conservation surgery and ipsilateral breast tumor recurrence. And it was widely used in clinical trials to accurate cosmetic grading, especially in clinical trials about breast irradiation ${ }^{24}$.

Poor and fair were included in the unsatisfied cosmetic outcome. EB PBI group has more risk of unsatisfied cosmetic outcome than WBI group ( $R R=1.56 ; 95 \% \mathrm{Cl}, 1.04$ to $2.34 ; \mathrm{p}=0.003, \mathrm{I}^{2}=84 \%$ ).

\section{acute skin toxicity ( $\mathbb{1}$ grade) and late skin toxicity ( $\mathbb{1}$ grade)}

Acute radiation morbidity scoring criteria and late radiation morbidity scoring scheme were from the Radiation Therapy Oncology Group(RTOG) and the European Organization for Research and Treatment of Cancer(EORTC) ${ }^{23,26-28}$. Acute skin toxicity greater than grade 1 should be treated for clinical. We mainly compared acute skin toxicity ( $\nabla 1$ grade) or late skin toxicity such as edema, pigmentation, depigmentation, telangiectasia, skin to atrophy, ulceration, and so on. 
EB PBI would cause less acute skin toxicity ( $₫ 1$ grade) than WBI ( $₫ 1$ grade) ( $R R=0.17 ; 95 \% \mathrm{Cl}, 0.07$ to $\left.0.42 ; \mathrm{p} \rrbracket 0.0001, \mathrm{I}^{2}=87 \%\right)$. $\mathrm{EB} \mathrm{PBI}$ has less late skin toxicity in WBI groups $(\mathrm{RR}=0.65 ; 95 \% \mathrm{Cl}, 0.48$ to 0.88 ; $\left.p=0.005 ; 1^{2}=27 \%\right)$.

Figure 2: Forest plots for outcomes. A: Local recurrence rates; B: Regional node recurrence; C: Contralateral breast cancer; D: Distant recurrence; E: Non-breast second cancer; F: Mortality; G: Cosmetic score; $\mathrm{H}$ : acute skin toxicity ( $\mathbb{1}$ grade); l: late skin toxicity.

\section{Discussion}

Studies about brachytherapy PBI or intraoperative PBI more than EB PBI. Our meta-analysis compared EB $\mathrm{PBI}$ and WBI which systemic proved that $\mathrm{EB} P B \mathrm{PI}$ has similar $\mathrm{LRR}$, regional node recurrence, contralateral breast cancer, distant recurrence, non-breast second cancer, and mortality with WBI for early breast patients. Besides, EB PBI has less acute skin toxicity ( $\triangle 1$ grade), similar late skin toxicity, and worse cosmetic score than WBI. The protection for subcutaneous tissue during radiotherapy plans delivery and limited the dose in EB PBI will contribute to better cosmetic outcomes. In the study we included, the dose of EB PBI was from $30 \mathrm{~Gy} / 5 \mathrm{f}$ to $40 \mathrm{~Gy} / 15 \mathrm{f}$. In the current report, the dose of EB PBI was 30-50Gy/5-10f, $\mathrm{QD} / \mathrm{BID}^{3,25,26,28,29}$. The best optimal dose of EB PBI radiation has not been determined, National Comprehensive Cancer Network(NCCN) recommend EB PBI deliver in the dose of 34 or $38.5 \mathrm{~Gy} / 10 \mathrm{f}$, BID and 40-42.5 Gy/15-16f, QD for WBI-accelerated. Dose of 4 studies is different which might the source of heterogeneity for LRR, cosmetic score, and acute skin toxicity ( $\nabla 1$ grade). TJ W ${ }^{23}$ 's study has a maximum proportion of patients. It was the main reason for heterogeneity for LRR and cosmetic score. It compared WBI-accelerated vs APBI, and the dose of it was the highest than other studies. Although its dose of WBIaccelerated and APBI was accepted by NCCN, Highest does and the different delivery fraction of irradiation might induce worst cosmetic score, LRR, local recurrence rates, mortality, and distant recurrence.

Yasmin Korzets et $\mathrm{al}^{16}$ fond that EB PBI may have the best control of local recurrence than brachytherapy $\mathrm{PBI}$ and IORT. EB PBI has similar local recurrence rate(LRR) with WBI. But they didn't include outcomes of RAPID ${ }^{23}$ and didn't evaluate regional recurrence, cosmetic score, acute, and late skin toxicity. Our study is the systematic meta-analysis of EB PBI versus WBI. We found that EB PBI had no significant difference in LRR, regional node recurrence, contralateral breast cancer, distant recurrence and mortality compared with WBI. These conclusions were similar to Yasmin Korzets's ${ }^{30}$ and Liu's ${ }^{18}$ study. But we found that EB $\mathrm{PBI}$ tends to increase the risk of LRR, decrease the risk of regional node recurrence, contralateral breast cancer, distant recurrence, and mortality, although all of them had no statistical difference between EB $\mathrm{PBI}$ and WBI groups.

The selection of PBI patients was controversial. NCCN, GEC-ESTRO, and UK guidelines recommend the patients suitable for PBI were as follows (Table 2). Different guidelines have different Selection criteria for low-risk early breast cancer patients. The patients that could deliver PBI were early breast stages with low recurrence risk. More studies were exploring the application and outcomes of PBI. NCCN guidelines 
recommend PBI was considered in patients as follows. (1) Older than 50 years old, T1, Negative margin $\geq 2 \mathrm{~mm}$, no LVI, ER-positive, and BRCA negative. (2) Low/medium nuclear grading. The measured size of DCIS detected by screening is less than $2.5 \mathrm{~cm}$ and the margin of the negative cutting edge is more than or equal to $3 \mathrm{~mm}$. GEC-ESTRO is similar to NCCN guidelines. In addition to the above inclusion criteria, UK consensus statements recommend that tumor size $\leqq 3 \mathrm{~cm}$ and negative her- 2 could also be considered for PBI. The inclusion criteria of PBI are still under discussion.

Table 2

NCCN, GEC-ESTRO, and UK guidelines recommend the patients suitable for PBI

\begin{tabular}{|c|c|c|c|}
\hline $\begin{array}{l}\text { Risk } \\
\text { factors }\end{array}$ & NCCN(ASTRO) & GEC-ESTRO & UK \\
\hline $\begin{array}{l}\text { Lymph } \\
\text { nodes }\end{array}$ & positive & positive & negative \\
\hline Margin & $\geq 2 \mathrm{~mm}$ & $\geq 2 \mathrm{~mm}$ & $\nabla 1-2 \mathrm{~mm}$ \\
\hline $\begin{array}{l}\text { Tumor } \\
\text { size }\end{array}$ & $\begin{array}{l}\leq 2 \mathrm{~cm} \text {, Single center, single tumor, no } \\
\text { vascular invasion } \square\end{array}$ & $\begin{array}{l}\leq 2 \mathrm{~cm}, \text { Non-central, } \\
\text { single tumor }\end{array}$ & $\leq 3 \mathrm{~cm}$ \\
\hline Garde & $1-2$ grade & - & $1-2$ grade \\
\hline $\begin{array}{l}\text { Hormonal } \\
\text { state }\end{array}$ & ER positive,BRACA negative & - & $\begin{array}{l}\text { ER positive,HER-2 } \\
\text { negative }\end{array}$ \\
\hline Age & $\geq 50$ years & $\geq 50$ years & $\geq 50$ years \\
\hline Dose & $38.5 \mathrm{~Gy} / 10 \mathrm{f}, \mathrm{BID}$ & $32 \mathrm{~Gy} / 8 f, b i d$ & $40 G Y / 15 f$ \\
\hline
\end{tabular}

[1] Rodriguez N, Sanz X, Dengra J, et al. Five-year outcomes, cosmesis, and toxicity with 3dimensional conformal external beam radiation therapy to deliver accelerated partial breast irradiation[J]. Int J Radiat Oncol Biol Phys, 2013, 87(5): 1051-7.

[2] Livi L, Meattini I, Marrazzo L, et al. Accelerated partial breast irradiation using intensity-modulated radiotherapy versus whole breast irradiation: 5-year survival analysis of a phase 3 randomised controlled trial[J]. Eur J Cancer, 2015, 51(4): $451-63$.

[3] Coles C E, Griffin C L, Kirby A M, et al. Partial-breast radiotherapy after breast conservation surgery for patients with early breast cancer (UK IMPORT LOW trial): 5-year results from a multicentre, randomised, controlled, phase 3, non-inferiority trial[J]. Lancet, 2017, 390(10099): 1048-1060.

[4] Tj W, Ja J, Ts B, et al. External beam accelerated partial breast irradiation versus whole breast irradiation after breast conserving surgery in women with ductal carcinoma in situ and node-negative breast cancer (RAPID): a randomised controlled trial[J]. Lancet (London, England), 2019, 394(10215): 2165-2172.

Table 2 NCCN, GEC-ESTRO, and UK guidelines recommend the patients suitable for PBI

Radiation can damage DNA, massive DNA damage and accumulation of unrepaired chromosome breaks induce cell death. Recurrence and metastasis were associated with tumor cells that did not die after radiotherapy. DNA damaged to activate not only $\mathrm{p} 16 / \mathrm{Rb}$ but also $\mathrm{p} 53 / \mathrm{p} 21$ pathway, all of them take importance of cellular senescence by cellular arrest and oncogene-induced senescence ${ }^{31}$. Irradiation 
induced the ATM kinase activated and p38 mitogen-activated protein kinase (MAPK) through reactive oxygen species (ROS), H2AX, and other DNA repair protein repair DNA damage by NHEJ, HR. Then, activating transcription factor nuclear factor kappa-B activates $\mathrm{pRb}$ by $\mathrm{p} 16 \mathrm{INK} 4 \mathrm{~A}$ ultimately induces durable cell-cycle arrest. Upregulation of inflammatory and fibrotic mediating, epigenetic changes, and disruption of normal oxygen metabolism will increase cytotoxicity reactive oxygen species (ROS) that occur within hours to years of exposure to ionizing radiation ${ }^{32}$. Apoptosis and senescence in cells trigger fibrosis through signaling pathways ${ }^{33}$. The key stages in the metastatic are the appearance of circulating tumor cells (CTCs) seeding and colonizing distant tissues and organs. EMT helps the tumor cells deform into a more metastasizing form. EMT is highly correlated with TGF- $\beta^{34}$. TGF- $\beta$ takes an important role in the process of preserving normal tissues, sensitizing tumor, pro-oxidant, and pro-fibrosis ${ }^{32,33}$.

EB PBI has less acute skin toxicity ( $\triangle 1$ grade), similar late skin toxicity, and worse cosmetic score than WBI which similar to Hickey $\mathrm{BE}^{20}$ et al 's study. Breast induration or fibrosis, atrophy, appearance changed, edema, the color of skin, fatty necrosis might affect the cosmetic score of EB PBI. The 4 studies we included in our meta-analysis were EB APBI vs WBI/WBI-accelerated. The dose of fraction of APBI mostly higher than WBI/WBI-accelerated which might induce worse toxicity in breast tissue. Patients in EB APBI groups got less irradiation exposure to normal tissue lead to less acute skin toxicity ( $\mathbb{1}$ grade). A higher dose of fraction and less irradiation exposure tissue affected cosmetic score and late skin toxicity. Livi $\mathrm{L}^{25}$ et al's study was the source of heterogeneity for acute skin toxicity because it has a minimum proportion of patients with acute skin toxicity in the EB PBI group. Moreover, all 3 studies show EB PBI would cause less acute skin toxicity ( $\mathbb{1} 1$ grade) than WBI.

The position of tumor bed will atrophy after surgery ${ }^{35-37}$. The accuracy of tumor bed in EB PBI was not similar to branch therapy and IORT. Moreover, incomplete coverage of potential tumor targets and increased exposure to normal tissues in EB PBI also needs to solve. The recommended PBI exposure range is $1-3 \mathrm{~cm}$ around the tumor bed ${ }^{23}$, it might incomplete coverage of potential target areas ${ }^{38}$. The different center has a different target area delineation standard. Different medical personnel had different delineation target area. But EB PBI has the largest irradiation range than beachy PBI and IORT which bring EB PBI better prognoses than PBI and IORT ${ }^{23}$. IMRT/VMRT can better fit the tumors than other technologies, the way of delivering irradiation will affect the results. Most PBI studies were about beachy $\mathrm{PBI}$ and IORT. But EB PBI was More economical, noninvasive, beautiful, easy to popularize.

In fact, increased irradiation exposure can kill potential cancer cells, but increased exposure to normal tissues such as heart, lung, and contralateral breast not necessarily lead to better outcomes. For PBI, the accurate selection of the population, the expansion of irradiation exposure range, and the adjustment of exposure mode still need to be further explored. There needs more study on EB PBI to help more and more early breast patients benefit from PBI.

\section{Conclusion}


This systematic review and meta-analysis found that EB PBI has similar LRR, regional node recurrence, contralateral breast cancer, distant recurrence, non-breast second cancer, and mortality with WBI. EB PBI has less acute skin toxicity ( $\nabla 1$ grade), similar late skin toxicity, and worse cosmetic score than WBI. EB PBI has a huge application prospect of clinical for early breast cancer patients. More studies about EB $\mathrm{PBI}$ are needed in the future.

\section{Declarations}

\section{Ethical Approval and Consent to participate}

Not applicable. All data are from published papers.

\section{Consent for publication}

The authors agree to publish the article.

\section{Availability of supporting data}

All the data are from published papers.

\section{Competing interests}

The authors declare no conflict of interest.

\section{Funding}

This work was supported by National Key Research and Development Program of China (No.2018YFC1311400/2018YFC1311402), Yunnan International Science and technology cooperation project (No.2018IA059), Yunnan Provincial Training Special Funds for High-level Health Technical Personnel (No. L-2018001), Ten-thousand Talents Program of Yunnan Province (Yunling scholar, Youth talent), Medical Reserve Personnel Training Plan of Yunnan Provincial Health Commissions (H-2018003), the Foundation of 100 Young and Middle-aged Academic and Technical Backbone of Kunming Medical University (60118260117), and Doctoral Innovation Fund of Kunming Medical University (2020D014).

\section{Authors' contributions}

Peiling Dai and Kai Chen completed the writing and partly design of the article. Lan Li and Li Wang completed literature retrieval and data collection. Yaoxiong Xia, Yu Hou and Lan Zhang completed the revision of the article. Li Chang and Wenhui Li completed the design of the article.

\section{Acknowledgements}

Thanks to the source of the article, the publication of the data made this article possible. Thanks to all the authors for their efforts. 
Synopsis: EB PBI has similar LRR, regional node recurrence, contralateral breast cancer, distant recurrence, non-breast second cancer and mortality with WBI. But EB PBI has worse cosmetic score, less acute skin toxicity ( $\nabla 1$ grade) and late skin toxicity than WBI.

\section{Data Availability Statement}

all data or used during the study are available in a repository or online in accordance with funder data retention policies (DOIs: 10.1016/j.ijrobp.2013.08.046; 10.1016/j.ejca.2014.12.013; 10.1016/s01406736(17)31145-5; 10.1016/s0140-6736(19)32515-2.)

\section{References}

1. Bray F, Ferlay J, Soerjomataram I, Siegel RL, Torre LA, Jemal A. Global cancer statistics 2018: GLOBOCAN estimates of incidence and mortality worldwide for 36 cancers in 185 countries. CA: a cancer journal for clinicians 2018;68:394-424.

2. Litiere S, Werutsky G, Fentiman IS, et al. Breast conserving therapy versus mastectomy for stage I-II breast cancer: 20 year follow-up of the EORTC 10801 phase 3 randomised trial. The Lancet Oncology 2012;13:412-9.

3. Darby S, McGale P, Correa C, et al. Effect of radiotherapy after breast-conserving surgery on 10-year recurrence and 15-year breast cancer death: meta-analysis of individual patient data for 10,801 women in 17 randomised trials. Lancet (London, England) 2011;378:1707-16.

4. Souchon R, Sautter-Bihl ML, Sedlmayer F, et al. DEGRO practical guidelines: radiotherapy of breast cancer II: radiotherapy of non-invasive neoplasia of the breast. Strahlentherapie und Onkologie : Organ der Deutschen Rontgengesellschaft [et al] 2014;190:8-16.

5. S G, WD K, M K, DL W, WJ M. The Effect of Waiting Times for Postoperative Radiotherapy on Outcomes for Women Receiving Partial Mastectomy for Breast Cancer: a Systematic Review and Meta-Analysis. Clinical oncology (Royal College of Radiologists (Great Britain)) 2016;28:739-49.

6. WJ G, BO A, J A, et al. Breast Cancer, Version 3.2020, NCCN Clinical Practice Guidelines in Oncology. Journal of the National Comprehensive Cancer Network : JNCCN 2020;18:452-78.

7. McCormick B. Partial breast radiation for early-stage breast cancer. Current opinion in obstetrics \& gynecology 2012;24:31-7.

8. FA V, RS C, JR W, et al. Long-term primary results of accelerated partial breast irradiation after breastconserving surgery for early-stage breast cancer: a randomised, phase 3, equivalence trial. Lancet (London, England) 2019;394:2155-64.

9. Sarin R. Partial-breast treatment for early breast cancer: emergence of a new paradigm. Nature clinical practice Oncology 2005;2:40-7.

10. Macdonald SM, Taghian AG. Partial-breast irradiation: towards a replacement for whole-breast irradiation? Expert review of anticancer therapy 2007;7:123-34. 
11. Hannoun-Levi JM, Marsiglia H, Garbay JR, Gerard JP. [Partial irradiation of the breast: why, how?]. Cancer radiotherapie : journal de la Societe francaise de radiotherapie oncologique 2003;7:200-9.

12. Hepel JT, Arthur D, Shaitelman S, et al. American Brachytherapy Society consensus report for accelerated partial breast irradiation using interstitial multicatheter brachytherapy. Brachytherapy 2017;16:919-28.

13. Ye XP, Bao S, Guo LY, et al. Accelerated partial breast irradiation for breast cancer: a meta-analysis. Translational oncology 2013;6:619-27.

14. Albuquerque K, Tell D, Lobo P, Millbrandt L, Mathews HL, Janusek LW. Impact of partial versus whole breast radiation therapy on fatigue, perceived stress, quality of life and natural killer cell activity in women with breast cancer. BMC cancer 2012;12:251.

15. Marta GN, Macedo CR, Carvalho Hde A, Hanna SA, da Silva JL, Riera R. Accelerated partial irradiation for breast cancer: systematic review and meta-analysis of 8653 women in eight randomized trials. Radiotherapy and oncology : journal of the European Society for Therapeutic Radiology and Oncology 2015;114:42-9.

16. Y K, A F, D S, E A, H G. Toxicity and clinical outcomes of partial breast irradiation compared to whole breast irradiation for early-stage breast cancer: a systematic review and meta-analysis. Breast cancer research and treatment 2019;175:531-45.

17. Vaidya JS, Bulsara M, Wenz F, et al. Reduced Mortality With Partial-Breast Irradiation for Early Breast Cancer: A Meta-Analysis of Randomized Trials. International journal of radiation oncology, biology, physics 2016;96:259-65.

18. Liu G, Dong Z, Huang B, et al. Efficacy and safety of accelerated partial breast irradiation: a metaanalysis of published randomized studies. Oncotarget 2017;8:59581-91.

19. Pan XB, Huang ST, Jiang YM, Ma JL, Zhu XD. Secondary malignancies after partial versus whole breast irradiation: a systematic review and meta-analysis. Oncotarget 2016;7:71951-9.

20. Hickey BE, Lehman M, Francis DP, See AM. Partial breast irradiation for early breast cancer. The Cochrane database of systematic reviews 2016;7:Cd007077.

21. B W, H H, GF F-U, et al. Prone accelerated partial breast irradiation after breast-conserving surgery: compliance to the dosimetry requirements of RTOG-0413. International journal of radiation oncology, biology, physics 2012;84:910-6.

22. Suh WW, Pierce LJ, Vicini FA, Hayman JA. A cost comparison analysis of partial versus whole-breast irradiation after breast-conserving surgery for early-stage breast cancer. International journal of radiation oncology, biology, physics 2005;62:790-6.

23. TJ W, JA J, TS B, et al. External beam accelerated partial breast irradiation versus whole breast irradiation after breast conserving surgery in women with ductal carcinoma in situ and node-negative breast cancer (RAPID): a randomised controlled trial. Lancet (London, England) 2019;394:2165-72.

24. M T, TB J, Y K, ED W, D P. The allegheny general modification of the Harvard Breast Cosmesis Scale for the retreated breast. Oncology (Williston Park, NY) 2009;23:954-6. 
25. Livi L, Meattini I, Marrazzo L, et al. Accelerated partial breast irradiation using intensity-modulated radiotherapy versus whole breast irradiation: 5-year survival analysis of a phase 3 randomised controlled trial. European journal of cancer (Oxford, England : 1990) 2015;51:451-63.

26. Coles CE, Griffin CL, Kirby AM, et al. Partial-breast radiotherapy after breast conservation surgery for patients with early breast cancer (UK IMPORT LOW trial): 5-year results from a multicentre, randomised, controlled, phase 3, non-inferiority trial. Lancet (London, England) 2017;390:1048-60.

27. JD C, J S, TF P. Toxicity criteria of the Radiation Therapy Oncology Group (RTOG) and the European Organization for Research and Treatment of Cancer (EORTC). International journal of radiation oncology, biology, physics 1995;31:1341-6.

28. Rodriguez N, Sanz X, Dengra J, et al. Five-year outcomes, cosmesis, and toxicity with 3-dimensional conformal external beam radiation therapy to deliver accelerated partial breast irradiation. International journal of radiation oncology, biology, physics 2013;87:1051-7.

29. Polgar C, Fodor J, Major T, Sulyok Z, Kasler M. Breast-conserving therapy with partial or whole breast irradiation: ten-year results of the Budapest randomized trial. Radiotherapy and oncology : journal of the European Society for Therapeutic Radiology and Oncology 2013;108:197-202.

30. Wang SL, Fang H, Song YW, et al. Hypofractionated versus conventional fractionated postmastectomy radiotherapy for patients with high-risk breast cancer: a randomised, non-inferiority, open-label, phase 3 trial. The Lancet Oncology 2019;20:352-60.

31. $\mathrm{HQ} \mathrm{N}, \mathrm{NH} T, \mathrm{P} Z$, et al. lonizing radiation-induced cellular senescence promotes tissue fibrosis after radiotherapy. A review. Critical reviews in oncology/hematology 2018;129:13-26.

32. E K, M H-G, P A, et al. Targets for protection and mitigation of radiation injury. Cellular and molecular life sciences : CMLS 2020.

33. B F, E K, M H-G, et al. TGF- $\beta$ in radiotherapy: mechanisms of tumor resistance and normal tissues injury. Pharmacological research 2020:104745.

34. YT L, KJ W. Epigenetic regulation of epithelial-mesenchymal transition: focusing on hypoxia and TGF- $\beta$ signaling. Journal of biomedical science 2020;27:39.

35. Kim LH, DeCesare S, Vicini F, Yan D. Effect of lumpectomy cavity volume change on the clinical target volume for accelerated partial breast irradiation: a deformable registration study. International journal of radiation oncology, biology, physics 2010;78:1121-6.

36. Prendergast B, Indelicato DJ, Grobmyer SR, et al. The dynamic tumor bed: volumetric changes in the lumpectomy cavity during breast-conserving therapy. International journal of radiation oncology, biology, physics 2009;74:695-701.

37. Kader HA, Truong PT, Pai R, et al. When is CT-based postoperative seroma most useful to plan partial breast radiotherapy? Evaluation of clinical factors affecting seroma volume and clarity. International journal of radiation oncology, biology, physics 2008;72:1064-9.

38. Landis DM, Luo W, Song J, et al. Variability among breast radiation oncologists in delineation of the postsurgical lumpectomy cavity. International journal of radiation oncology, biology, physics 2007;67:1299-308. 


\section{Figures}

\section{Reviewer 1}

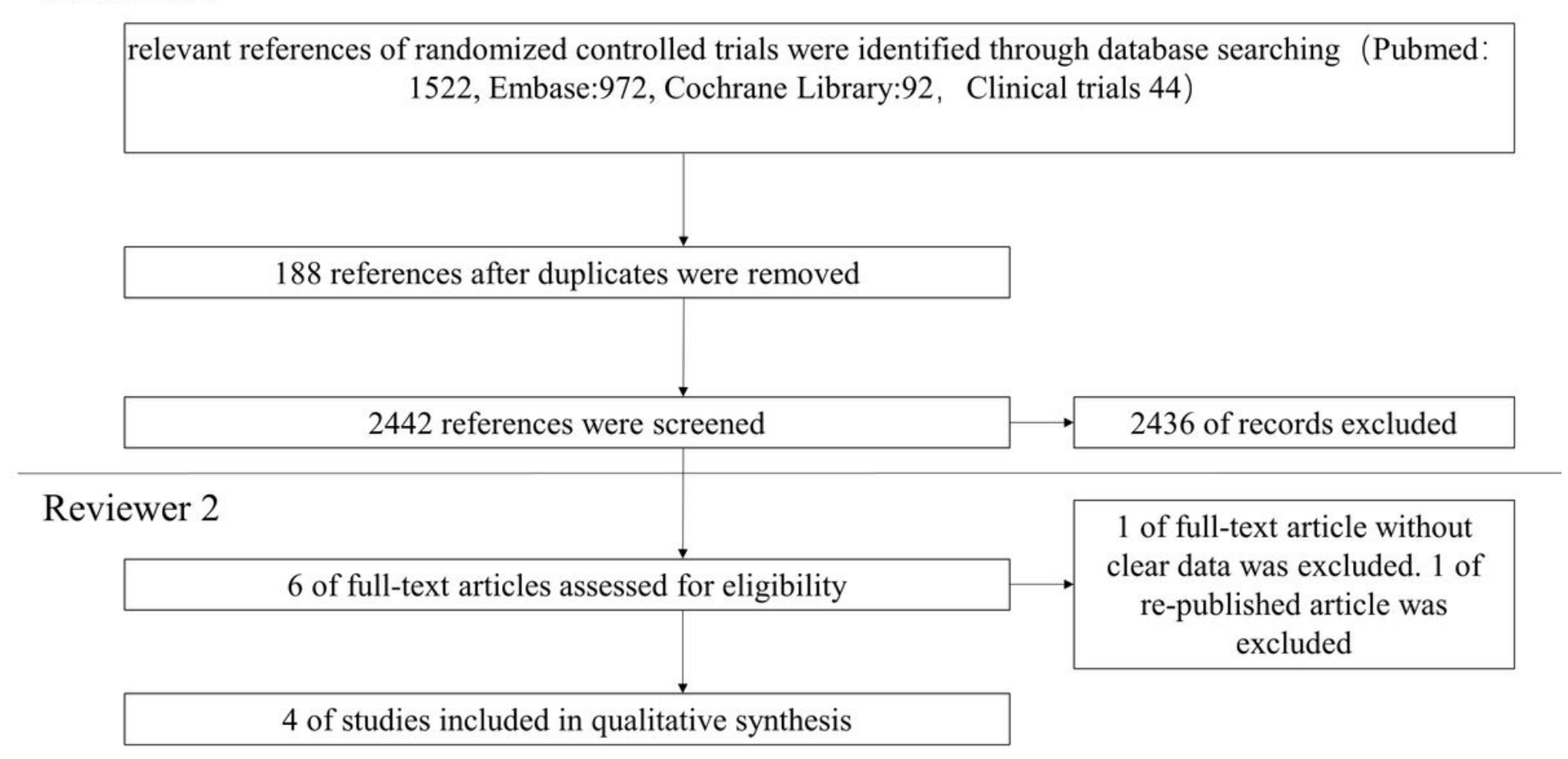

\section{Figure 1}

Study selection scheme. 


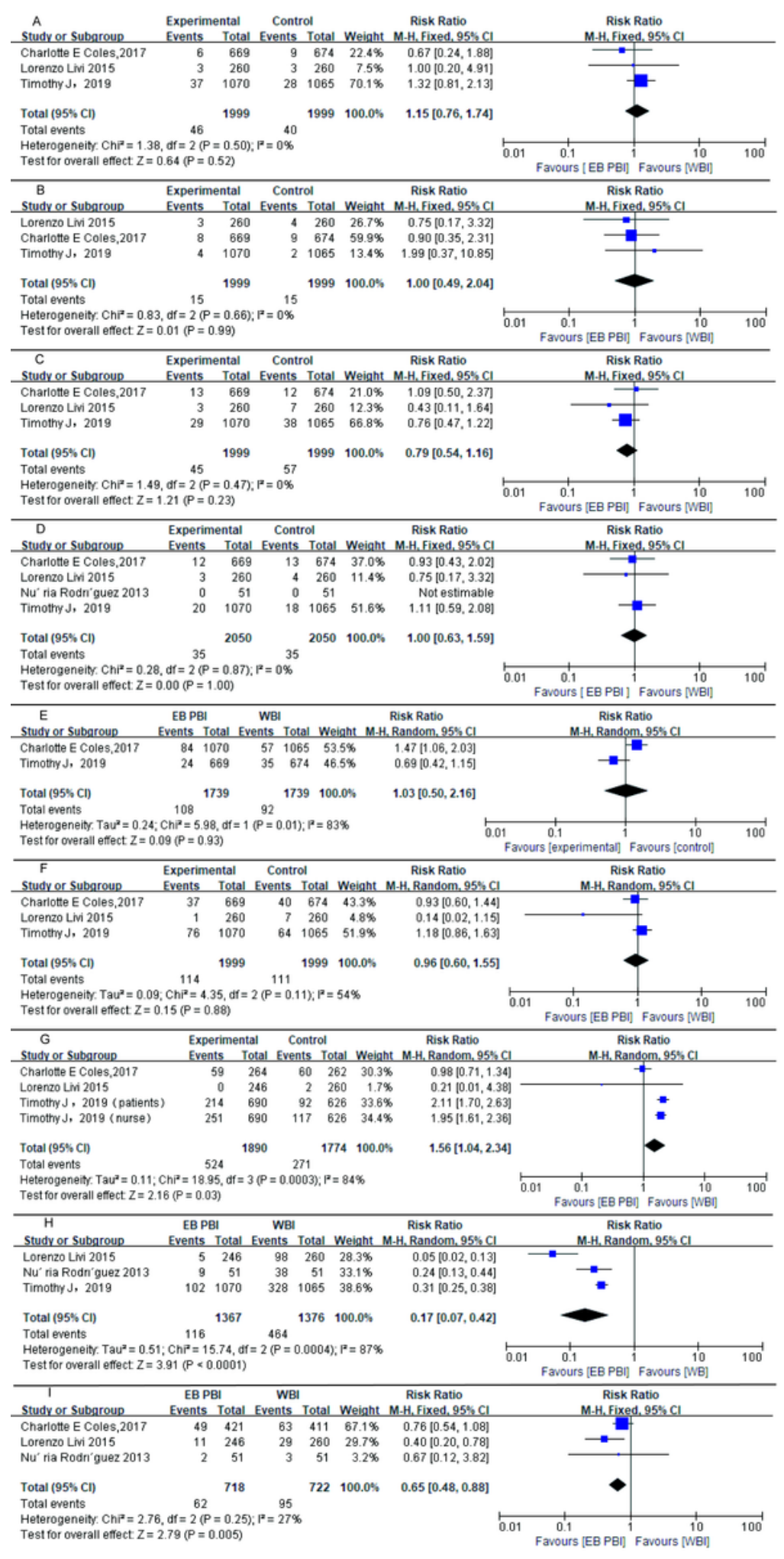

Figure 2

Forest plots for outcomes. A: Local recurrence rates; B: Regional node recurrence; C: Contralateral breast cancer; D: Distant recurrence; E: Non-breast second cancer; F: Mortality; G: Cosmetic score; H: acute skin toxicity ( $₫ 1$ grade); I: late skin toxicity. 